\title{
The contradictory effect of macrophage-related cytokine expression in lumbar disc herniations: a systematic review
}

\author{
N. Djuric ${ }^{1}$. . G. C. M. Lafeber ${ }^{1}$. C. L. A. Vleggeert-Lankamp ${ }^{1}$
}

Received: 15 April 2019 / Revised: 10 October 2019 / Accepted: 9 November 2019 / Published online: 25 November 2019

(c) The Author(s) 2019

\begin{abstract}
Purpose Sciatic symptoms due to lumbar disc herniation are likely to be caused not solely by mechanical compression of the nerve root, but also by pain-inducing elements from inflammatory processes. Key components in the inflammatory reaction are M1 and M2 macrophages, with the M1 type being associated with pro-inflammatory processes and M2 with anti-inflammatory-processes.

Method The present systematic review summarizes all studies on associations between M1 and M2 macrophages and their related inflammation factors and pain symptoms in lumbar disc herniations. Literature search was performed using an optimally sensitive search string. Studies were selected for inclusion by means of predefined inclusion and exclusion criteria and subsequently graded for risk of bias. A total of 14 studies were included. Overall risk of bias was moderate (8/14), and three studies had high risk of bias and three has low risk of bias.

Results Regarding M1-related cytokines, high levels of TNF- $\alpha$, TNFR1, IL-6, IL-8, and IFN- $\gamma$ were all associated high VAS scores. In contrast, high levels of TNFR2 were associated with lower VAS scores. Moreover, no associations were found for IL-1a and IL-1 $\beta$. Results regarding M2-related cytokines revealed the opposite: high levels of both IL-4 and IL-10 were associated with lower VAS scores. No associations were established for TGF- $\beta$. Moreover, the presence of macrophages (CD68) was negatively associated with VAS scores.

Conclusion While M1-related pro-inflammatory cytokines worsen pain symptoms, M2-related anti-inflammatory cytokines alleviate pain symptoms. Nevertheless, the present evidence is limited, and further research on the underlying pathophysiological mechanism in sciatica is required.
\end{abstract}

\section{Graphic abstract}

These slides can be retrieved under Electronic Supplementary Material.
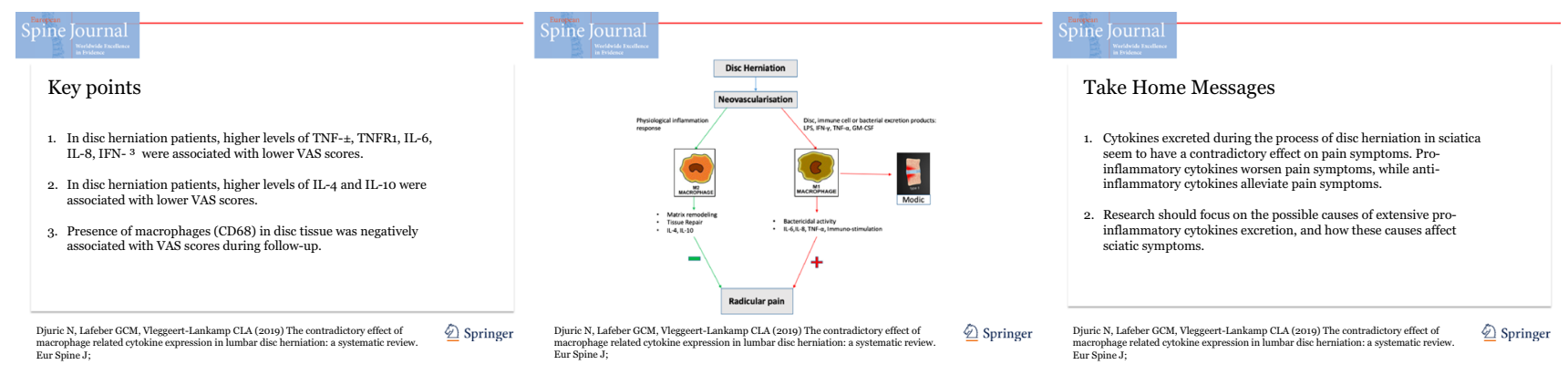

Keywords Sciatica $\cdot$ Cytokine $\cdot$ Macrophage $\cdot$ Disc $\cdot$ Inflammation

Electronic supplementary material The online version of this article (https://doi.org/10.1007/s00586-019-06220-w) contains supplementary material, which is available to authorized users.

Extended author information available on the last page of the article 


\section{Introduction}

At present, one of the most prevalent causes for physical disability is herniation of the intervertebral disc. When a disc herniates, it often causes compression of the nerve root, which leads to a radiating pain alongside the dermatome, often referred to as sciatica [1,2]. At first sight, the cause for sciatica seems purely mechanical, but the observation of nerve root compression due to disc herniation in $20-76 \%$ of asymptomatic cases suggests that mechanical compression is not the only factor at play [3-5].

Over the past two decades several researchers suggested that inflammation of the nerve root and/or disc plays a significant role in sciatica [4, 6-8]. It is hypothesized that nucleus pulposus (NP) material that herniates into the epidural space induces a foreign-body reaction that involves macrophage infiltration [8]. These macrophages are not only suggested to play a role in resorption of herniated disc material [4, 5, 9], but also suggested to, at least partially, play a role in inducing an inflammatory response. This could in turn cause pain. The different roles of macrophages are reflected in the contradictory views of experts and physicians. Any discrepancy in these roles may be dependent on the type of macrophage present in the disc material.

Present literature distinguishes M1 and M2 macrophages [10]. A M1 macrophage can be differentiated from a monocyte if stimulated by lipopolysaccharide (LPS) or interferon-gamma (IFN- $\gamma$ ) or tumour necrosis factor (TNF), or granulocyte macrophage colony-stimulating factor (GM-CSF). M1 produces pro-inflammatory cytokines and products such as IL-1, IL- $1 \alpha$, IL- $1 \beta$, IL-6, IL-8, IL-12, IL-18, IL-23 IL-27, TNF- $\alpha$, and Bone Morphogenic Protein 2 (BMP-2) [10-12]. The main focus of this type is microbicidal activity [11], and its expression profile is associated with exacerbation of pain symptoms [13]. On the contrary, if a monocyte is stimulated by IL-4, IL-10, and IL-13, glucocorticoids or macrophage colonystimulating factor (M-CSF), it differentiates into M2 macrophage. This alternative type of macrophage excretes anti-inflammatory cytokines such as IL-1Ra, IL-10, and transforming growth factor-beta (TGF- $\beta$ ) [11], which are involved in multiple functions such as tissue repair and remodelling $[10,11,14]$. In contrast to the effect of M1 macrophages, M2 is believed to alleviate pain symptoms through resorption of herniated disc material [15]. During most inflammation processes, M1 or M2 macrophages occur sequentially [11]. However, depending on the disease and genetic predisposition, their ratios may vary widely [11]. Despite extensive research in the field of sciatica, the role of M1 and M2 macrophages remains to be elucidated. A better understanding of these processes could lead to improved prognostics and personalized treatment. The aim of the present study is therefore to systematically review all literature concerning the role of macrophages and their related pro- and anti-inflammatory cytokines and factors in lumbar disc herniation patients suffering from sciatic symptoms.

\section{Materials and methods}

\section{Inclusion criteria}

Studies with patients suffering from sciatica were to be included if the study analysed the correlation between the presence of macrophages or their related cytokines and/or excretion factors, as verified by serum, CSF, or disc material samples, and quantitatively measured clinical outcome parameters.

\section{Search and selection}

The electronic databases Medline (from 1960), EMBASE (from 1947) and Web of Science (from 1960) where searched up until February 2018. A search string in order to systematically explore all studies that included presence of macrophages or their related cytokines and factors was constructed and adapted per database. Eligible studies were selected on title and abstract by two independent review authors (ND and GL), with consensus meeting and referee (CVL) available, according to PRISMA guidelines. If the abstract alone did not provide sufficient information, the full paper was assessed. Afterwards, citation tracking was performed and further eligible studies were acquired.

The search strategy comprised strings for sciatica and macrophages, granulocyte macrophage colony-stimulating factor (GM-CSF), interferon-gamma (IFN- $\gamma$ ), tumour necrosis factor- $\alpha$ (TNF- $\alpha$ ), tumour necrosis factor-beta (TNF-b), Bone Morphogenic Protein 2 (BMP-2), tumour growth factor-beta (TGF- $\beta$ ), IL-1, IL-1 $\alpha$, IL-1Ra, IL-1 $\beta$, IL-4, IL-6, IL-8, IL-10, IL-12, IL-13, IL-18, and IL-27. No restrictions on publication date were made, and all articles were to be fully published in English. Conference proceedings were excluded. The included studies had to consist of a minimum of 10 patients suffering from acute, sub-acute or chronic pain in lumbar disc herniation. No restrictions were made on follow-up. Furthermore, studies were only included if clinical outcome was measured reporting a pain scale, the straight leg raising test (SLR) or the Oswestry disability index (ODI). Pains scales are the visual analogue scale (VAS) leg pain or a comparable scale like the visual rating scale (VRS) for pain or the numeric rating scale (NRS) for pain. The ODI scale evaluates the functionality focussing on the leg and back. Additionally, studies were excluded 
if they failed to specify which cytokine or excretion factor was present, or if the cytokine or excretion factor was not measured in serum, CSF, or disc material.

\section{Quality assessment}

Two authors (ND, GL) reviewed the methodological quality of all included articles individually, using an adjusted version of the scoring criteria by Cowley (Supplementary Table 1) [16], in which a maximum of 10 points can be given. Risk of bias was deemed low if the Cowley score was $\geq 8$, moderate between 5 and 7 and high risk of bias with a score of 0-4. Differences in quality assessment between the two reviewers were justified in a consensus meeting.

\section{Data extraction}

The primary outcome of the present study comprises associations between macrophage-related parameters and pain symptoms. From each study, basic information was gathered concerning authors (sponsoring, affiliation), methods (study design, sample size and type of analysis), patients (source population, inclusion criteria, exclusion criteria, baseline characteristics, and diagnostic characteristics), treatments (interventions), outcome variables and results.

\section{Results}

\section{Study selection}

The search in the PubMed database yielded 305 results, EMBASE yielded 585 and Web of Science yielded 272 results. In total, 1162 references were obtained. After removal of duplicates, 755 remained. After abstract and full-text screening, 14 articles met inclusion criteria. Subsequently, citation tracking was applied, which did not lead to any additional findings. Hence the final number of included articles was fourteen (Fig. 1).

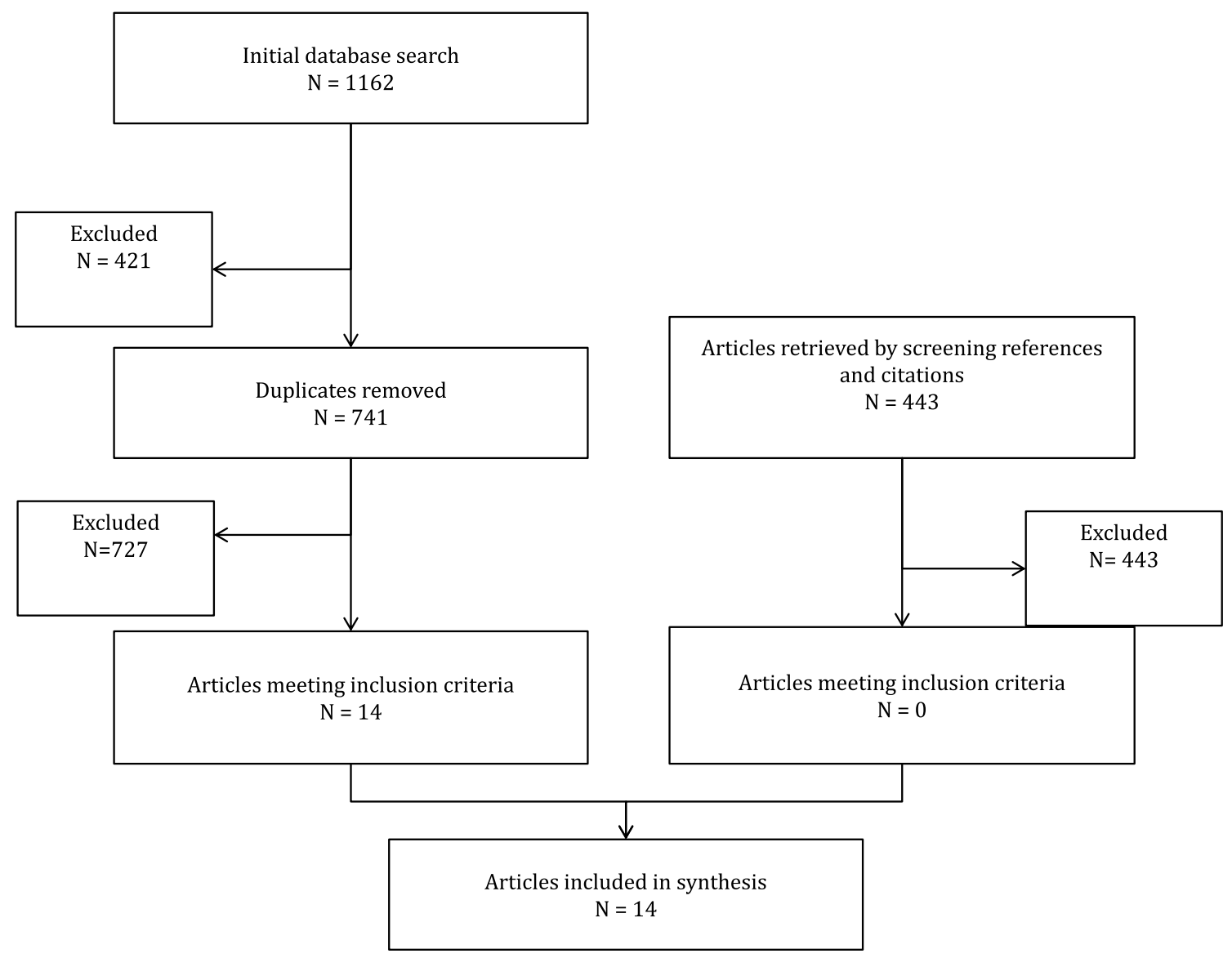

Fig. 1 Flowchart of the database search. From the initial database search 1175 articles were obtained, of which 741 remained after removal of duplicates. Fourteen articles from the initial search met the inclusion criteria. After citation tracking, 443 articles were found. After the duplicates were removed and the inclusion criteria were applied, no articles were used from the citation tracking 


\section{Risk of bias assessment}

Of the 14 studies, three were scored to have low, eight to have moderate and three to have high risk of bias. Regarding individual categories, first, risk of population bias was generally moderate, and all studies reported age and sex, whereas only five studies provided specific and explicit inclusion and exclusion criteria for lumbar disc herniation [13, 17-20]. Second, selection bias could be ruled out in six studies and was also regarded as generally moderate [13, 17, 18, 20-22]. Third, risk of outcome bias was generally considered moderate as well; most studies clearly defined outcome measures except for Schistad et al. [18]. Here, the authors described IL-8 measurements in the method section but failed to elaborate on them in the results [18]. If studies failed to test parametric test assumptions for VAS scores, no points for statistical analyses were awarded [13, 18, 20, 21, 23-25]. None of the studies described clinical evaluation as independent of the treating physician. Fourth, the selected studies showed a low risk of attrition bias, as all of the 14 selected articles were prospective studies. Eight studies had a follow-up period longer than 6 months in all described studies [13, 18, 20, 22-24, 26]. Finally, only five studies explicitly reported to have no conflict of interest [18-20,23]. An overview of the risk of bias scores is provided in Table 1 .

\section{Data extraction: macrophages and related cytokines and factors}

The reported methods of measuring macrophages, cytokines and excretion factors varied widely. Some authors histologically described their presence in nucleus pulposus material that was taken out during surgery, others looked at presence of macrophages and accompanying inflammatory factors in blood or cerebral spinal fluid. Moreover, the choice of parameter studied varied widely. Not all the parameters that are associated with M1 and M2 macrophages were reported in the studies that were eligible for this review. The histological parameter for macrophages, CD68 (surface marker), was reported in a few studies. M1-related factors that were encountered are: interferon-gamma (IFN- $\gamma$ ), tumour necrosis factor alpha (TNF- $\alpha$ ), tumour necrosis factor receptor 1/2 (TNFR1/TNFR2), and M1-related cytokines that were reported are: IL- $1 \alpha$, IL-1 $\beta$, IL-6, IL- 8 and IL-12. M2-related factors that were reported in the articles are: tumour growth factor-beta (TGF- $\beta$ ), and the M2-related cytokines that were reported are: IL-4 and IL-10.

\section{Association between macrophage marker and pain}

Two out of the four studies on CD68 $[22,26]$ found a negative association with pain scores during follow-up [22, 26-28], and one study found a negative association with straight leg raising test [28], which means that patients with higher CD68 (macrophage) expression had less pain and lower SLR scores.

\section{Association between pro-inflammatory factors (M1) and clinical outcome}

In studies examining the association of TNF- $\alpha$ with VAS pain or SLR or ODI, five out of six studies found a positive
Table 1 Overview of the risk of bias

\begin{tabular}{lllllll}
\hline Study (year of publication) & $\begin{array}{l}\text { Score on risk of } \\
\text { bias scale }\end{array}$ & $P$ & $S$ & $O$ & $A$ & $I$ \\
\hline Ahn et al. [17] & $6 / 10$ & $3 / 3$ & $1 / 1$ & $1 / 3$ & $1 / 2$ & $0 / 1$ \\
Andrade et al. [24] & $6 / 10$ & $1 / 3$ & $0 / 1$ & $2 / 3$ & $2 / 2$ & $1 / 1$ \\
Andrade et al. [42] & $6 / 10$ & $1 / 3$ & $0 / 1$ & $2 / 3$ & $2 / 2$ & $1 / 1$ \\
Andrade et al. [23] & $5 / 10$ & $2 / 3$ & $0 / 1$ & $1 / 3$ & $2 / 2$ & $0 / 1$ \\
Brisby et al. [25] & $4 / 10$ & $1 / 3$ & $0 / 1$ & $2 / 3$ & $1 / 2$ & $0 / 1$ \\
Cuellar et al. [21] & $5 / 10$ & $2 / 3$ & $1 / 1$ & $1 / 3$ & $1 / 2$ & $0 / 1$ \\
Pedersen et al. [13] & $8 / 10$ & $3 / 3$ & $1 / 1$ & $2 / 3$ & $2 / 2$ & $0 / 1$ \\
Rothoerl et al. [27] & $3 / 10$ & $1 / 3$ & $0 / 1$ & $1 / 3$ & $1 / 2$ & $0 / 1$ \\
Acta Neurochirurgica & & & & & & \\
Rothoerl et al. [26] & $5 / 10$ & $1 / 3$ & $0 / 1$ & $2 / 3$ & $2 / 2$ & $0 / 1$ \\
Rothoerl et al. [27] & $3 / 10$ & $1 / 3$ & $0 / 1$ & $1 / 3$ & $1 / 2$ & $0 / 1$ \\
Spine & & & & & & \\
Schistad et al. [18] & $8 / 10$ & $3 / 3$ & $1 / 1$ & $1 / 3$ & $2 / 2$ & $1 / 1$ \\
Wang et al. [19] & $6 / 10$ & $1 / 3$ & $1 / 1$ & $1 / 3$ & $2 / 2$ & $0 / 1$ \\
Woertgen et al. [22] & $5 / 10$ & $3 / 3$ & $1 / 1$ & $2 / 3$ & $2 / 2$ & $1 / 1$ \\
Zu et al. [20] & $8 / 10$ & & & & & \\
\hline
\end{tabular}

This table shows the overall risk of bias and the individual categories

$P$ population bias, $S$ selection bias, $o$ outcome bias, $A$ attrition bias, $I$ conflict of interest 
association [17, 19, 20, 23-25], which means that patients with higher TNF- $\alpha$ levels had higher pain scores. The only study that did not find such association had a high risk of bias [25]. In most studies, TNF- $\alpha$ association with clinical parameters was evaluated at baseline, but in follow-up data, the association remained present $[20,24]$. Both studies on TNFR1, a TNF- $\alpha$ receptor, found a positive association with pain scores, one at baseline [23], and both during follow-up [23, 24]. In contrast, the same studies found that TNFR2 had a negative association with pain scores, which means that patients with high levels of TNFR2 reported lower pain scores $[23,24]$. Three out of five studies on IL-6 found a positive association with pain scores and ODI $[13,18,19,23,25]$. One of the studies that did not find an association had high risk of bias [25]. The other study that did not demonstrate an association between pain and IL- 6 determined the IL- 6 concentration in disc material, while the three studies that did find a positive correlation examined IL-6 in serum (Table 2).

Two out of four studies on IL-8 found a positive association with pain scores and SLR [13, 17, 19, 25]; one of these studies examined IL-8 in disc material [17], and the other in serum [13]. Two out of four studies on IL-8 found no association with pain scores, SLR or ODI, one of these studies (high risk of bias [25]) examined IL-8 in CSF and the other study examined IL-8 in serum [19].

All three studies on IL- $1 \beta$ showed no association with pain scores and SLR $[23,25]$. The IL- $1 \beta$ expression was examined in disc material, CSF and serum. The study on IL-1a found no association with pain scores [17].

Two studies examined the association of IFN- $\gamma$ with pain or SLR and did not find an association [21, 25]. However, one of these studies had a high risk of bias [25], and the other examined the association with several VAS cutoff scores, thereby inducing outcome bias [21].

\section{Association between anti-inflammatory factors (M2) and clinical outcomes}

Two studies examining IL-10 demonstrated different results $[17,19]$. One study did not demonstrate an association with pain score or SLR [17]. The other study demonstrated a negative association: in patients with higher pain scores or ODI, the concentration of IL-10 in serum was lower as compared to patients with a low pain score or ODI [19] (Table 2).

One of the two studies on IL-4 found a negative association with pain scores at 12-month follow-up [20]. The other study demonstrated no association with VAS or ODI [19]. The study on TGF- $\beta$ found no association with pain or SLR [17].

\section{Discussion}

The present systematic review established associations between the presence of macrophages and their proinflammatory and anti-inflammatory cytokines with pain and/or disability in lumbar disc herniation. Because of the heterogeneity in outcome measures and data presentation, only a qualitative analysis was performed. Also, methodological quality of the studies varied widely. For the M1-related factors, literature presented moderate evidence for associations between high pain scores and high levels of TNF- $\alpha$, TNFR1 and IL- 6 , limited evidence for associations between high pain scores and high levels of IL-8, no associations between pain-related outcome measures and IL- $1 \alpha$, IL- $1 \beta$ or IFN-gamma, and moderate evidence for an association between low pain scores and high levels of TNFR2. In contrast, for the M2-related factors, evidence with moderate quality was found for an association between low pain scores and high levels of IL-4, limited evidence for an association between low pain scores and high levels of IL-10, and no association was found with TGF-beta.

\section{Associations between inflammation markers and clinical outcomes}

Primary outcome measures were sciatic symptoms and cytokines and other macrophage-related parameters. The present review specifically included studies that measured pain symptoms expressed by VAS and/or ODI scores and/ or SLR. These clinical symptoms were subsequently correlated to inflammatory parameters. The tissue or fluid in which these parameters were examined varied among studies. Some studies looked at mRNA [17, 23, 24] or protein expression patterns $[21,23,24]$ in the nucleus pulposus or annulus fibrosis, while others measured concentrations of cytokines in CSF [25] or blood [13, 18-20, 25]. Other studies examined macrophage infiltration histologically [22, 26-28] in herniated disc tissue. The comparability of the studies included for review is therefore rather limited, and these differences could hence have confounded our results.

The most convincing positive association between pain-related outcome measures and M1 excretion factors was provided by studies on TNF- $\alpha$. Five out of six studies examining TNF- $\alpha$ expression patterns indicate that higher pain scores associate with a higher protein and mRNA expression intensity in the nucleus pulposus [17, 23, 24], and with higher serum concentrations $[19,20,25]$. Of these studies, one had low risk of bias [20] and four had moderate risk of bias [19]. Only the study with lowest 
Table 2 An overview of the evidence on the associations between macrophage infiltration, M1-related or M2-related factors and the clinical outcomes

\begin{tabular}{|c|c|c|c|c|c|}
\hline Study (year of publication) & Cohort size $(n)$ & Risk of bias & Specification & Clinical parameter & Association \\
\hline \multicolumn{6}{|l|}{ CD68 macrophage marker } \\
\hline $\begin{array}{l}\text { Rothoerl et al. [27] (Acta } \\
\text { Neurochirurgica) }\end{array}$ & 179 & $3 / 10$ & Disc infiltration & $\begin{array}{l}\text { Pre-op pain (VAS) } \\
\text { Pre-op SLR }\end{array}$ & $\begin{array}{l}\text { No } \\
\text { No }\end{array}$ \\
\hline Rothoerl et al. [26] & 177 & $6 / 10$ & Disc infiltration & $\begin{array}{l}\text { Pre-op pain (VAS) } \\
\text { 7-month FU pain (VAS) } \\
\text { Pre-op SLR }\end{array}$ & $\begin{array}{l}\text { No } \\
\text { Neg } \\
\text { No }\end{array}$ \\
\hline Rothoerl et al. [27] (Spine) & 44 & $4 / 10$ & Disc infiltration & $\begin{array}{l}\text { Pre-op pain (VAS) } \\
\text { Pre-op SLR }\end{array}$ & $\begin{array}{l}\text { No } \\
\text { Neg }\end{array}$ \\
\hline Woertgen et al. [22] & 79 & $5 / 10$ & Disc infiltration & $\begin{array}{l}\text { Pre-op SLR } \\
\text { Pre-op pain (VAS) } \\
\text { 6-month FU pain (VAS) }\end{array}$ & $\begin{array}{l}\text { No } \\
\text { No } \\
\text { Neg }\end{array}$ \\
\hline \multicolumn{6}{|l|}{ M1 expression profile } \\
\hline \multicolumn{6}{|l|}{ TNF- $\alpha$} \\
\hline Ahn et al. [17] & 23 & $5 / 10$ & mRNA expression NP & $\begin{array}{l}\text { Pre-op pain (VAS) } \\
\text { Pre-op SLR }\end{array}$ & $\begin{array}{l}\text { Pos } \\
\text { Pos }\end{array}$ \\
\hline Andrade et al. [24] & 15 & $8 / 10$ & $\begin{array}{l}\text { Protein expression NP/AF } \\
\text { mRNA expression NP/AF }\end{array}$ & $\begin{array}{l}\text { Pre-op pain (VAS) } \\
\text { 6-week FU pain (VAS) } \\
\text { 12-month FU pain (VAS) } \\
\text { Pre-op pain (VAS) } \\
\text { 6-week FU pain (VAS) } \\
\text { 12-month FU pain (VAS) }\end{array}$ & $\begin{array}{l}\text { No/no } \\
\text { Pos/no } \\
\text { Pos/no } \\
\text { No/no } \\
\text { Pos/no } \\
\text { Pos/no }\end{array}$ \\
\hline Andrade et al. [23] & 20 & $5 / 10$ & $\begin{array}{l}\text { Protein expression } \\
\text { mRNA expression }\end{array}$ & $\begin{array}{l}\text { Pre-op pain (VAS) } \\
\text { 6-month FU pain (VAS) } \\
\text { VAS }<3.5 \text { vs }>3.5\end{array}$ & $\begin{array}{l}\text { Pos } \\
\text { Pos } \\
\text { Pos }\end{array}$ \\
\hline Brisby et al. [25] & 39 & $3 / 10$ & CSF and serum concentration & $\begin{array}{l}\text { Pre-op pain (VAS) } \\
\text { Pre-op SLR }\end{array}$ & $\begin{array}{l}\text { No } \\
\text { No }\end{array}$ \\
\hline Wang et al. [19] & 138 & $6 / 10$ & Serum concentration & $\begin{array}{l}\text { Pre-op pain (VAS) } \\
\text { Pre-op ODI }\end{array}$ & $\begin{array}{l}\text { Pos } \\
\text { Pos }\end{array}$ \\
\hline $\mathrm{Zu}$ et al. [20] & 262 & $9 / 10$ & $\begin{array}{l}\text { Serum concentration at baseline } \\
\text { Serum concentration at } 1 \text {-month FU } \\
\text { Serum concentration at } 12 \text {-month FU }\end{array}$ & $\begin{array}{l}\text { 12-month FU pain (VAS) } \\
\text { 12-month FU pain (VAS) } \\
\text { 12-month FU pain (VAS) } \\
\text { 12-month FU ODI }\end{array}$ & $\begin{array}{l}\text { Pos } \\
\text { Pos } \\
\text { Pos } \\
\text { Pos }\end{array}$ \\
\hline \multicolumn{6}{|l|}{ TNFR1 } \\
\hline Andrade et al. [24] & 15 & $8 / 10$ & Protein expression NP/AF & $\begin{array}{l}\text { Pre-op pain (VAS) } \\
\text { 6-week FU pain (VAS) } \\
\text { 12-month FU pain (VAS) }\end{array}$ & $\begin{array}{l}\text { Pos/pos } \\
\text { Pos/no } \\
\text { Pos/no }\end{array}$ \\
\hline Andrade et al. [23] & 20 & $5 / 10$ & $\begin{array}{l}\text { Protein expression } \\
\text { mRNA expression }\end{array}$ & $\begin{array}{l}\text { Pre-op pain (VAS) } \\
\text { 6-month FU pain (VAS) } \\
\text { Pre-op pain VAS }\end{array}$ & $\begin{array}{l}\text { Pos } \\
\text { Pos } \\
\text { Pos }\end{array}$ \\
\hline \multicolumn{6}{|l|}{ TNFR2 } \\
\hline Andrade et al. [24] & 15 & $8 / 10$ & Protein expression NP/AF & $\begin{array}{l}\text { Pre-op pain (VAS) } \\
\text { 6-week FU pain (VAS) } \\
\text { 12-month FU pain (VAS) }\end{array}$ & $\begin{array}{l}\text { No/neg } \\
\text { No/neg } \\
\text { No/neg }\end{array}$ \\
\hline Andrade et al. [23] & 20 & $5 / 10$ & $\begin{array}{l}\text { Protein expression } \\
\text { mRNA expression }\end{array}$ & $\begin{array}{l}\text { Pre-op pain (VAS) } \\
\text { 6-month FU pain (VAS) } \\
\text { Pre-op pain VAS }\end{array}$ & $\begin{array}{l}\text { Neg } \\
\text { Neg } \\
\text { Neg }\end{array}$ \\
\hline \multicolumn{6}{|l|}{ IL-6 } \\
\hline Andrade et al. [42] & 15 & $8 / 10$ & $\begin{array}{l}\text { mRNA expression NP/AF } \\
\text { protein expression NP/AF }\end{array}$ & $\begin{array}{l}\text { Pre-op pain (VAS) } \\
\text { 6-week FU pain (VAS) } \\
\text { 12-month FU pain (VAS) } \\
\text { Pre-op pain (VAS) } \\
\text { 6-week FU pain (VAS) } \\
\text { 12-month FU pain (VAS) }\end{array}$ & $\begin{array}{l}\text { No/no } \\
\text { No/no } \\
\text { No/no } \\
\text { No/no } \\
\text { No/no } \\
\text { No/no }\end{array}$ \\
\hline Brisby et al. [25] & 39 & $3 / 10$ & CSF and serum concentration & $\begin{array}{l}\text { Pre-op pain (VAS) } \\
\text { Pre-op SLR }\end{array}$ & $\begin{array}{l}\text { No } \\
\text { No }\end{array}$ \\
\hline
\end{tabular}


Table 2 (continued)

\begin{tabular}{|c|c|c|c|c|c|}
\hline Study (year of publication) & Cohort size $(n)$ & Risk of bias & Specification & Clinical parameter & Association \\
\hline Pedersen et al. [13] & 127 & $8 / 10$ & Serum concentration & 12-month FU pain (VAS) & Pos \\
\hline Schistad et al. [18] & 54 & $7 / 10$ & Serum concentration & $\begin{array}{l}\text { ODI baseline-1 year FU } \\
\text { 12-month FU back pain (VAS) } \\
\text { 12-month FU leg pain (VAS) }\end{array}$ & $\begin{array}{l}\text { Pos } \\
\text { Pos } \\
\text { Pos }\end{array}$ \\
\hline Wang et al. [19] & 138 & $6 / 10$ & Serum concentration & $\begin{array}{l}\text { Pre-op pain (VAS) } \\
\text { Pre-op ODI }\end{array}$ & $\begin{array}{l}\text { Pos } \\
\text { Pos }\end{array}$ \\
\hline \multicolumn{6}{|l|}{ IL-8 } \\
\hline Ahn et al. [17] & 23 & $5 / 10$ & mRNA expression NP & $\begin{array}{l}\text { Pre-op pain (VAS) } \\
\text { Pre-op SLR }\end{array}$ & $\begin{array}{l}\text { Pos } \\
\text { Pos }\end{array}$ \\
\hline Brisby et al. [25] & 39 & $3 / 10$ & CSF concentration & $\begin{array}{l}\text { Pre-op pain (VAS) } \\
\text { Pre-op SLR }\end{array}$ & $\begin{array}{l}\text { No } \\
\text { No }\end{array}$ \\
\hline Pedersen et al. [13] & 127 & $8 / 10$ & Serum concentration & 12-month FU pain (VAS) & Pos \\
\hline Wang et al. [19] & 138 & $6 / 10$ & Serum concentration & $\begin{array}{l}\text { Pre-op pain (VAS) } \\
\text { Pre-op ODI }\end{array}$ & $\begin{array}{l}\text { No } \\
\text { No }\end{array}$ \\
\hline \multicolumn{6}{|l|}{ IL-1 $\beta$} \\
\hline Ahn et al. [17] & 23 & $5 / 10$ & mRNA expression NP & $\begin{array}{l}\text { Pre-op pain (VAS) } \\
\text { Pre-op SLR }\end{array}$ & $\begin{array}{l}\text { No } \\
\text { No }\end{array}$ \\
\hline Andrade et al. [42] & 15 & $8 / 10$ & $\begin{array}{l}\text { mRNA expression NP/AF } \\
\text { protein expression NP/AF }\end{array}$ & $\begin{array}{l}\text { Pre-op pain (VAS) } \\
\text { 6-week FU pain (VAS) } \\
\text { 12-month FU pain (VAS) } \\
\text { Pre-op pain (VAS) } \\
\text { 6-week FU pain (VAS) } \\
\text { 12-month FU pain (VAS) }\end{array}$ & $\begin{array}{l}\text { No/no } \\
\text { No/no } \\
\text { No/no } \\
\text { No/no } \\
\text { No/no } \\
\text { No/no }\end{array}$ \\
\hline Brisby et al. [25] & 39 & $3 / 10$ & CSF and serum concentration & $\begin{array}{l}\text { Pre-op pain (VAS) } \\
\text { Pre-op SLR }\end{array}$ & $\begin{array}{l}\text { No } \\
\text { No }\end{array}$ \\
\hline \multicolumn{6}{|l|}{ IL- $1 \alpha$} \\
\hline Ahn et al. [17] & 23 & $5 / 10$ & mRNA expression NP & $\begin{array}{l}\text { Pre-op pain (VAS) } \\
\text { Pre-op SLR }\end{array}$ & $\begin{array}{l}\text { No } \\
\text { No }\end{array}$ \\
\hline \multicolumn{6}{|l|}{ IFN- $\gamma$} \\
\hline Brisby et al. [25] & 39 & $3 / 10$ & CSF and serum concentration & $\begin{array}{l}\text { Pre-op pain (VAS) } \\
\text { Pre-op SLR }\end{array}$ & $\begin{array}{l}\text { No } \\
\text { No }\end{array}$ \\
\hline $\begin{array}{l}\text { Cuellar et al. [21] } \\
\text { M2 expression profile } \\
\text { IL-10 }\end{array}$ & 24 & $5 / 10$ & Protein expression NP & Pre-op VAS & Pos \\
\hline Ahn et al. [17] & 23 & $5 / 10$ & mRNA expression NP & $\begin{array}{l}\text { Pre-op pain (VAS) } \\
\text { Pre-op SLR }\end{array}$ & $\begin{array}{l}\text { No } \\
\text { No }\end{array}$ \\
\hline Wang et al. [19] & 138 & $6 / 10$ & Serum concentration & $\begin{array}{l}\text { Pre-op pain (VAS) } \\
\text { ODI }\end{array}$ & $\begin{array}{l}\mathrm{Neg} \\
\mathrm{Neg}\end{array}$ \\
\hline \multicolumn{6}{|l|}{ IL-4 } \\
\hline Wang et al. [19] & 138 & $6 / 10$ & Serum concentration & $\begin{array}{l}\text { Pre-op pain (VAS) } \\
\text { ODI }\end{array}$ & $\begin{array}{l}\text { No } \\
\text { No }\end{array}$ \\
\hline Zu et al. [20] & 262 & $9 / 10$ & $\begin{array}{l}\text { Serum concentration at baseline } \\
\text { Serum concentration at } 1 \text {-month FU } \\
\text { Serum concentration at } 12 \text {-month FU }\end{array}$ & $\begin{array}{l}\text { 12-month FU pain (VAS) } \\
\text { 12-month FU pain (VAS) } \\
\text { 12-month FU pain (VAS) } \\
\text { 12-month FU ODI }\end{array}$ & $\begin{array}{l}\text { Neg } \\
\text { Neg } \\
\text { Neg } \\
\text { No }\end{array}$ \\
\hline \multicolumn{6}{|l|}{ TGF- $\beta$} \\
\hline Ahn et al. [17] & 23 & $5 / 10$ & mRNA expression NP & $\begin{array}{l}\text { Pre-op pain (VAS) } \\
\text { Pre-op SLR }\end{array}$ & $\begin{array}{l}\text { No } \\
\text { No }\end{array}$ \\
\hline
\end{tabular}

'No' infers that no association was established. If an association is indicated as 'positive', the inflammatory factor positively association to the clinical outcome parameter (as an example: 'Andrade [24]': if the TNFR1 expression was higher, patients experienced more postoperative pain). 'Negative' infers a negative association between the inflammatory and clinical outcome parameter in question. As an example: in Andrade [24], high TNFR2 expression associated with less postoperative pain. The negative associations indicate a protective effect of an inflammatory reaction on pain or disability. Of these fourteen studies, three used a correlation test instead of an association test: Brisby et al. [25], Cuellar et al. [21], Wang et al. [19].

$N P$ nucleus pulposus, $A F$ annulus fibrosis, $F U$ follow-up, $P r e$-op pre-operative, $P o s$ positive association, Neg negative association 
quality could not establish an association between inflammation and clinical outcome [25]. These findings suggest that lowering TNF- $\alpha$ levels with drugs such as TNF- $\alpha$ blockers may alleviate sciatic symptoms. The efficacy of TNF- $\alpha$ inhibitors has recently been reviewed by Wang et al. [19] and Williams et al. [29]. Both studies concluded that evidence supporting anti-inflammatory agents, as a means of therapy in sciatica, is present but not yet convincing. Combining these results with the findings from the present systematic literature review, we suggest the lack of convincing evidence of the previous reviews may be explained by the fact that TNF- $\alpha$ levels vary among patients, which diminishes the overall efficacy of TNF- $\alpha$ inhibitors when given to all sciatica patients instead of only the subpopulation with actual high TNF- $\alpha$ levels. In order to properly evaluate the efficacy of these inhibitors, an RCT that only includes patients with high TNF- $\alpha$ levels is needed.

\section{Previous systematic reviews}

Our findings are in agreement with previous systematic literature reviews and meta-analyses. Goupille et al. [30] were the first to identify inflammatory mediators in disc herniation, and to suggest that inflammation is involved in sciatic symptom development. However, the literature of 1998 failed to provide evidence for the suggested involvement. The present literature review is the first to specifically outline all established associations between different cytokines and other macrophage-related inflammatory factors involved in sciatica on clinical outcomes.

\section{Clinical implications and recommendations}

Our current treatment for radicular pain is conservative care for a period of 8-12 weeks; however, if symptoms persist however, a surgical intervention is offered [31]. Unfortunately, even after surgery, some patients do not recover satisfactorily. As of today, it remains unclear why nerve decompression does not lead to pain reduction. Recent evidence by Lama et al. [32] showed that in some discs cartilage fragments were found and that in these discs only little swelling and infiltration of immune cells was present. The authors suggested that cartilage fragments could interfere with the resorption process, which could be an explanation for the abovementioned variety in recovery rate. The presence of cartilage fragments in the intervertebral disc may be caused by a defect in the endplate. Moreover, endplate defects are known to increase permeability of the intervertebral disc, thereby increasing the risk of infection in the endplate. Preclinical findings suggest that when an inflammatory response is induced in mice discs by bacteria, increasing nerve outgrowth from the dorsal root ganglion into the disc consequently occurs [33]. Nerve outgrowth could subsequently lead to sensitization of the disc, thereby facilitating pain symptoms. Currently, the evidence for this theory is still limited and further exploration of these concepts is required.

Nevertheless, recent clinical studies are in line with the abovementioned findings and show that discs of some lumbar disc herniation patients were infected with Propionibacterium acnes or Staphylococcus epidermidis [34, 35]. In addition, Dudli [36] induced herniated disc samples with $P$. acnes and found that six out 10 discs responded with excretion of pro-inflammatory cytokines. This inflammatory response was associated with endplate defects on MRI, more often described as Modic changes [37, 38]. Likewise, others have associated the presence of Modic changes with a slower recovery after surgery [39], and a chronic inflammatory response. However, other factors than bacterial infection may induce a shift of macrophage differentiation towards M1 macrophages and induce the excretion of pro-inflammatory cytokines, for instance, endplate pathology, or an innate defect in macrophage differentiation [40].

Even though the abovementioned findings are still inconclusive, it has inspired the following theory (Fig. 2): patients who suffer from disc inflammation without any complicating factors such as bacterial infection, endplate pathology or immune defects will show a response that is dominated by M2 macrophages, which excrete anti-inflammatory cytokines such as IL-4 and IL-10. This type of inflammation will likely induce a resorption process and may thus be beneficial to the patient. On the contrary, if patients show an inflammation reaction of the disc with one of the abovementioned complicating factors, the reaction is likely to be mediated by M1 macrophages and pro-inflammatory products such as IL-6, IL-8, TNF- $\alpha$ and IFN- $\gamma$, originating from the disc and/or endplate. This type of inflammation will likely aggravate the symptoms of the patients and could be recognised by presence of Modic changes on MRI.

As mentioned earlier, current evidence for this theory is limited, and the underlying pathophysiological mechanism should be further explored before this theory can be confirmed. Hence we recommend that future studies focus on exploring the possible causes of macrophage differentiation towards M1 and the excretion of pro-inflammatory cytokines, and how the different causes affect symptoms of sciatica.

Moreover, despite the fact that inflammation has shown to play a significant role in sciatica, the impact of mechanical compression should not be forgotten. Inflammation only occurs in a fraction of the patients [41], indicating that for many, the pain has a mechanical origin that can be alleviated through decompression [31]. Nonetheless, in many cases, both the mechanical and the inflammatory component will attribute to the sciatic symptoms. For such cases, it remains 
Fig. 2 Proposed hypothesis. Disc inflammation with M2 macrophage dominance is beneficial for the pain symptoms, whereas a dominance of M2 macrophages, likely induced by a bacterial infection and recognizable by Modic changes, will aggravate the pain symptoms

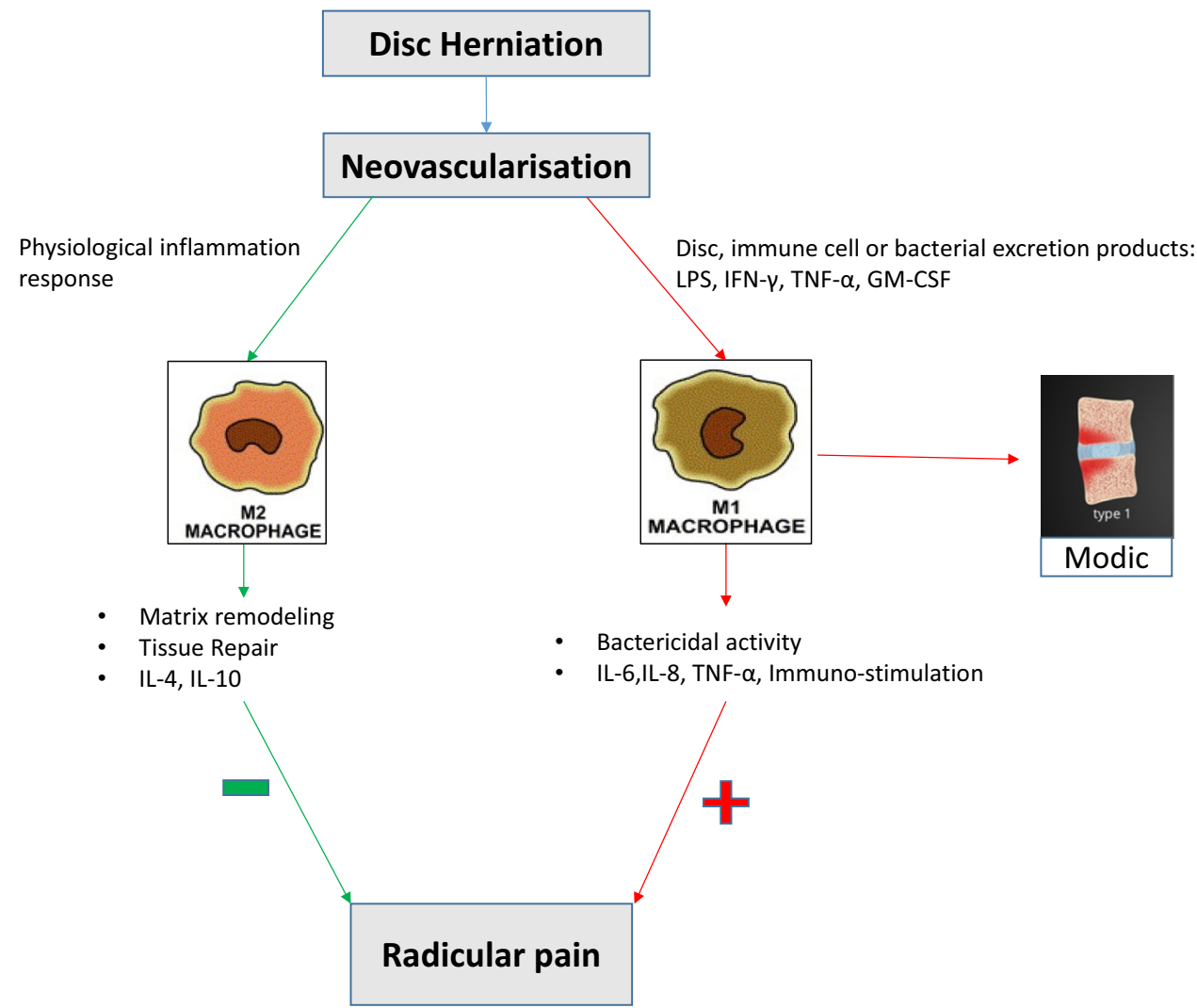

difficult to define how much each component contributes to the experienced pain, since excision of the hernia will not only relieve the compression, but also a part of inflammation, which was present in the herniated part. Likewise, antiinflammatory agents are usually studied in a population that contains both patients with and without inflammation. This attenuates the reported effect of the anti-inflammatory agents and prevents us from finding the real effect size of inflammation. This stresses the importance of taking inflammation into consideration in a study population. By doing so, steps can be made in delivering a more personalized treatment that takes the heterogeneity of sciatica into account.

\section{Limitations of our study}

Because this review only assessed Embase, PubMed and Web of Science, relevant studies that are hidden elsewhere might have been missed. Furthermore, the criteria used for risk of bias assessment included arbitrary cut of points, such as duration of follow-up, exclusion criteria and validity of statistical analysis (Supplementary Table 1). Therefore, the risk of bias scores given to the evaluated studies may alter in a different review, which could lead to different qualities of evidence for the found associations. At last, this review was only able to include 14 papers, and thus only has a limited amount of evidence to draw conclusions from.
This illustrates that more studies on this topic are needed in order to validate the results from previous trials and further explore the role of inflammation in sciatica.

\section{Conclusion}

Cytokines excreted during the process of disc herniation in sciatica seem to have a contradicting effect on pain symptoms. Pro-inflammatory cytokines worsen pain symptoms, while anti-inflammatory cytokines alleviate pain symptoms.

Acknowledgements We would like express special thanks to Dr. N. van der Werf, whose assistance on composing an optimally sensitive search string was of indispensable value for the present study.

Funding No funding was received for the conductance of this study.

\section{Compliance with ethical standards}

Conflict of interest The authors declare that they have no conflict of interest.

Open Access This article is distributed under the terms of the Creative Commons Attribution 4.0 International License (http://creativeco mmons.org/licenses/by/4.0/), which permits unrestricted use, distribution, and reproduction in any medium, provided you give appropriate credit to the original author(s) and the source, provide a link to the Creative Commons license, and indicate if changes were made. 


\section{References}

1. Mixter WJ, Bar J (1934) Rupture of intervertebral disc with involvement of spinal canal. N Engl J Med 211(210):5

2. Robinson JS (1983) Sciatica and the lumbar-disk syndrome-a historic perspective. South Med J 76(2):232-238

3. Jensen MC, Brant-Zawadzki MN, Obuchowski N et al (1994) Magnetic resonance imaging of the lumbar spine in people without back pain. N Engl J Med 331(2):69-73

4. Takada E, Takahashi M, Shimada K (2001) Natural history of lumbar disc hernia with radicular leg pain: spontaneous MRI changes of the herniated mass and correlation with clinical outcome. J Orthop Surg (Hong Kong) 9(1):1-7

5. Yukawa Y, Kato F, Matsubara Y et al (1996) Serial magnetic resonance imaging follow-up study of lumbar disc herniation conservatively treated for average 30 months: relation between reduction of herniation and degeneration of disc. J Spinal Disord 9(3):251-256

6. Marshal LL, Trethewie ER, Curtain CC (1977) Chemical radiculitis-clinical, physiological and immunological study. Clin Orthop Relat Res 129:61-67

7. Masui T, Yukawa Y, Nakamura S et al (2005) Natural history of patients with lumbar disc herniation observed by magnetic resonance imaging for minimum 7 years. J Spinal Disord Tech 18(2):121-126

8. Lohr M, Lebenheim L, Berg F et al (2014) Gadolinium enhancement in newly diagnosed patients with lumbar disc herniations are associated with inflammatory peridiscal tissue reactionsevidence of fragment degradation? Clin Neurol Neurosurg 119:28-34

9. Arai Y, Yasuma T, Shitoto K et al (2000) Immunohistological study of intervertebral disc herniation of lumbar spine. J Orthop Sci 5(3):229-231

10. Arango Duque G, Descoteaux A (2014) Macrophage cytokines: involvement in immunity and infectious diseases. Front Immunol 5:491

11. Martinez FO, Gordon S (2014) The M1 and M2 paradigm of macrophage activation: time for reassessment. F1000Prime Rep 6:13

12. Dube PR, Birnbaumer L, Vazquez G (2017) Evidence for constitutive bone morphogenetic protein- 2 secretion by M1 macrophages: constitutive auto/paracrine osteogenic signaling by BMP-2 in M1 macrophages. Biochem Biophys Res Commun 491(1):154-158

13. Pedersen LM, Schistad E, Jacobsen LM et al (2015) Serum levels of the pro-inflammatory interleukins 6 (IL-6) and -8 (IL-8) in patients with lumbar radicular pain due to disc herniation: a 12-month prospective study. Brain Behav Immun 46:132-136

14. Martinez FO, Helming L, Gordon S (2009) Alternative activation of macrophages: an immunologic functional perspective. Annu Rev Immunol 27:451-483

15. Peluffo H, Solari-Saquieres P, Negro-Demontel ML et al (2015) CD300f immunoreceptor contributes to peripheral nerve regeneration by the modulation of macrophage inflammatory phenotype. J Neuroinflammation 12:145

16. Cowley DE (1995) Prostheses for primary total hip replacement. A critical appraisal of the literature. Int J Technol Assess Health Care 11(4):770-778

17. Ahn SH, Cho YW, Ahn MW et al (2002) mRNA expression of cytokines and chemokines in herniated lumbar intervertebral discs. Spine (Phila Pa 1976) 27(9):911-917

18. Schistad EI, Espeland A, Pedersen LM et al (2014) Association between baseline IL-6 and 1-year recovery in lumbar radicular pain. Eur J Pain 18(10):1394-1401
19. Wang YF, Chen PY, Chang W et al (2014) Clinical significance of tumor necrosis factor-alpha inhibitors in the treatment of sciatica: a systematic review and meta-analysis. PLoS ONE 9(7):e103147

20. Zu B, Pan H, Zhang XJ et al (2016) Serum levels of the inflammatory cytokines in patients with lumbar radicular pain due to disc herniation. Asian Spine J 10(5):843-849

21. Cuellar JM, Golish SR, Reuter MW et al (2010) Cytokine evaluation in individuals with low back pain using discographic lavage. Spine J 10(3):212-218

22. Woertgen C, Rothoerl RD, Brawanski A (2000) Influence of macrophage infiltration of herniated lumbar disc tissue on outcome after lumbar disc surgery. Spine (Phila Pa 1976) 25(7):871-875

23. Andrade P, Hoogland G, Teernstra OP et al (2016) Elevated levels of tumor necrosis factor-alpha and TNFR1 in recurrent herniated lumbar discs correlate with chronicity of postoperative sciatic pain. Spine J 16(2):243-251

24. Andrade P, Visser-Vandewalle V, Philippens M et al (2011) Tumor necrosis factor-alpha levels correlate with postoperative pain severity in lumbar disc hernia patients: opposite clinical effects between tumor necrosis factor receptor 1 and 2. Pain 152(11):2645-2652

25. Brisby H, Olmarker K, Larsson K et al (2002) Proinflammatory cytokines in cerebrospinal fluid and serum in patients with disc herniation and sciatica. Eur Spine J 11(1):62-66

26. Rothoerl RD, Woertgen C, Brawanski A (2002) Pain resolution after lumbar disc surgery is influenced by macrophage tissue infiltration. A prospective consecutive study on 177 patients. J Clin Neurosci 9(6):633-636

27. Rothoerl R, Woertgen C, Holzschuh M et al (1998) Macrophage tissue infiltration, clinical symptoms, and signs in patients with lumbar disc herniation. A clinicopathological study on 179 patients. Acta Neurochir (Wien) 140(12):1245-1248

28. Rothoerl RD, Woertgen C, Holzschuh M et al (1998) Is there a clinical correlate to the histologic evidence of inflammation in herniated lumbar disc tissue? Spine (Phila Pa 1976) 23(11):1197-1200; discussion 1200-1201

29. Williams NH, Lewis R, Din NU et al (2013) A systematic review and meta-analysis of biological treatments targeting tumour necrosis factor alpha for sciatica. Eur Spine J 22(9):1921-1935

30. Goupille P, Jayson MI, Valat JP et al (1998) The role of inflammation in disk herniation-associated radiculopathy. Semin Arthritis Rheum 28(1):60-71

31. Peul WC, van Houwelingen HC, van den Hout WB et al (2007) Surgery versus prolonged conservative treatment for sciatica. $\mathrm{N}$ Engl J Med 356(22):2245-2256

32. Lama P, Zehra U, Balkovec C et al (2014) Significance of cartilage endplate within herniated disc tissue. Eur Spine J 23(9):1869-1877

33. Aoki Y, Ohtori S, Ino H et al (2004) Disc inflammation potentially promotes axonal regeneration of dorsal root ganglion neurons innervating lumbar intervertebral disc in rats. Spine (Phila Pa 1976) 29(23):2621-2626

34. Ganko R, Rao PJ, Phan K et al (2015) Can bacterial infection by low virulent organisms be a plausible cause for symptomatic disc degeneration? A systematic review. Spine (Phila Pa 1976) 40(10):E587-E592

35. Rajasekaran S, Tangavel C, Aiyer SN et al (2017) ISSLS PRIZE IN CLINICAL SCIENCE 2017: is infection the possible initiator of disc disease? An insight from proteomic analysis. Eur Spine J 26(5):1384-1400

36. Dudli S, Miller S, Demir-Deviren S et al (2017) Inflammatory response of disc cells against Propionibacterium acnes depends on the presence of lumbar Modic changes. Eur Spine J 27(5):1013-1020 
37. Modic MT, Masaryk TJ, Ross JS et al (1988) Imaging of degenerative disk disease. Radiology 168(1):177-186

38. Modic MT, Steinberg PM, Ross JS et al (1988) (1988) Degenerative disk disease: assessment of changes in vertebral body marrow with MR imaging. Radiology 166(1 Pt 1):193-199

39. Shan Z, Fan S, Xie Q et al (2014) Spontaneous resorption of lumbar disc herniation is less likely when Modic changes are present. Spine (Phila Pa 1976) 39(9):736-744

40. Vida C, de Toda IM, Cruces J et al (2017) Role of macrophages in age-related oxidative stress and lipofuscin accumulation in mice. Redox Biol 12:423-437
41. Djuric N, Yang X, el Barzouhi A et al (2019) Gadolinium enhancement is not associated with disc inflammation in patients with sciatica. Spine (Phila Pa 1976) 44(12):E742-E748

42. Andrade P, Hoogland G, Garcia MA et al (2013) Elevated IL1 beta and IL-6 levels in lumbar herniated discs in patients with sciatic pain. Eur Spine J 22(4):714-720

Publisher's Note Springer Nature remains neutral with regard to jurisdictional claims in published maps and institutional affiliations.

\section{Affiliations}

\section{N. Djuric ${ }^{1}$ - G. C. M. Lafeber ${ }^{1} \cdot$ C. L. A. Vleggeert-Lankamp ${ }^{1}$}

$\triangle$ N. Djuric

n.djuric@lumc.nl
Department of Neurosurgery, Leiden University Medical Center, Albinusdreef 2, 2300 RC Leiden, the Netherlands 